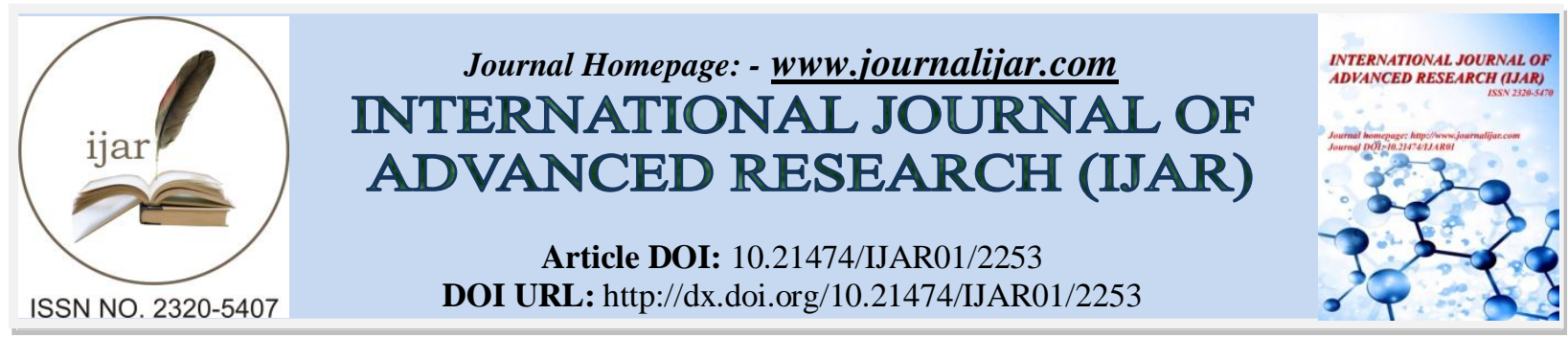

RESEARCH ARTICLE

\title{
BIOLOGICAL IMPACT OF MORINGA OLEIFERA EXTRACT ON PAROTID GLAND OF CISPLATIN- INDUCED RENAL FAILURE IN ALBINO RATS.
}

Amira A. R. Moawad, Mohammed Abdulrahman Mohammed, Fatma M. Ibrahim and Ahmed R.Zaher.

Oral Biology Department, Faculty of Dentistry, Mansoura University, Egypt.

\section{Manuscript Info}

Manuscript History

Received: 29 September 2016

Final Accepted: 30 October 2016

Published: November 2016

\section{Abstract}

Background:- Cisplatin is a major antineoplasticdrug for the treatment of solid tumors, but it has dose-dependent renal toxicity.

Aim:- in the present study we reported the effect of moringa oleifera extract on the parotid gland of cisplatin- induced renal failure of albino rats.

Material and methods:- Adult male albino rats were divided into three treated groups and control group of 12 rats each,1. Control rats I, (6 $\mathrm{mg} / \mathrm{kg}$ body wt. of saline by i.p. injection and repeated after 2 weeks). 2. Study groups (II, III and IV) induction of renal failure done by single i.p. injection of $6 \mathrm{mg} / \mathrm{kg}$ body wt. of cisplatin in group III, while in group II and IV this dose was repeated after 2 weeks, 4 days later after the first injection of cisplatin blood samples were collected for creatinine level analysis. In group III after the blood analysis animals received $5 \mathrm{mg} / \mathrm{kg}$ body wt. /day of moringa oleifera extract for 2 weeks. In group IV after the second injection of cisplatin, animals received the same dose of moringa oleifera extract for 2 weeks. Animals were sacrificed at 2 intervals, in group I: after $18 \& 32$ days from the start of experiment. In group II: after collection of blood samples\&1 week later.in group III and IV at the end of moringa treatment\& 1 week later.

Results:- Cisplatin administration induced renal failure which was accompanied by increase in serum creatinine level and manifested histologically in parotid gland as cracks like vacuolations, widening of connective tissue septa, loss of acinar outlines and hydropic degeneration. The administration of moringa minimized the cytotoxic effect of cisplatin in group III \& IV which was detected by decrease in serum creatinine level, and evidenced histologically as densely packed serous acini with regular basally located nuclei having symmetrical shape and size restoring its normal pattern.

Conclusion:- These results suggest that moringa oleifera extract protect against the effect of renal failure on parotid gland. 


\section{Introduction:-}

The changes induced by cisplatin in the kidney functions were characterized by signs of injury, such as changes in urine volume, in glutathione status, increase of products of lipid peroxidation, and changes in creatinine clearance, ${ }^{\mathbf{1}}$. Cisplatin also induces a reduction in antioxidant status, leading to a failure of the antioxidant defense against freeradical damage generated by antitumor drugs, ${ }^{2,3}$.

The cytotoxic (anticancer) effects of cisplatin are due to coordinative bonds between the atom of platinum and DNA of the cells leading to formation intra strand DNA crosslinks. This interaction of cisplatin with nuclear DNA may have important cellular effects contributing to apoptosis, ${ }^{3-6}$.Cisplatin also may directly lead to the generation of reactive oxygen species or may induce the release of reactive oxygen molecules normally sequestered within mitochondria that may trigger several mechanisms of apoptosis. Reactive oxygen species mediated damage could occur as consequence of antioxidant depletion and increased lipid peroxidation, ${ }^{7}$.

Moringa oleifera commonly known as "Miracle Tree" or "Mother's Best Friend" is the best known and most widely distributed species of Moringaceae family, having an impressive range of medicinal uses with high nutritional value throughout the world, ${ }^{\mathbf{8}, 9}$. All parts of the Moringa tree are edible and have long been consumed by humans. It is reported to contain alkaloids, flavonoids, anthocyanins, proanthocyanidins and cinnamates, ${ }^{\mathbf{1 0}}$. Traditionally it is used in the treatment of Influenza, fever, giddiness, nervous debility, hysteria, articular pains, spasmodic affections of the bowel, ${ }^{\mathbf{9}}$ worm infestations, diabetes, ${ }^{\mathbf{1 1}}$ as rubefacients, carminative, stomachic, abortifacient, flatulence ${ }^{\mathbf{1 2}}$ and in chronic rheumatism, ${ }^{11,13}$.

It was reported that Moringa leaf is a potential source of natural antioxidants such as total phenolics and antioxidant vitamin A, C and E, ascorbic acid oxidase, polyphenol oxidase and catalase, ${ }^{\mathbf{1 4}, 15}$. The leaves are a rich source of essential amino acids such as methionine, cysteine, tryptophan, lysine, vitamins and minerals. ${ }^{\mathbf{1 6}}$ Fresh leaves are used as an herbal medicine in treating a wide variety of diseases in Bangladesh and India. Moringa leaves have been reported to act as a hypo-cholesterolemic agent, thyroid hormone regulator, anti-diabetic agent, antitumor agent and hypotensive agent, ${ }^{17-22}$.

\section{Material and methods:-}

48 adult male albino rats weighing from 150-200 gm were used in this study. The animals were housed in individual cages and receive standard food for rodents and tap water. The rats were divided into 4 equal groups (12 rats each) as follow:

Group I:- control group, animals were received $6 \mathrm{mg} / \mathrm{kg}$ body wt. of saline by i.p. injection which repeated after 2 weeks.

Sacrification of the animals in group I was done at $\mathbf{2}$ intervals as follow:-

Firstly 6 random animals were sacrificed after 18 days from the start of experiment.

Secondly the remaining 6 animals were sacrificed after 32 days from the start of experiment.

Group II: At day zero the animals were received i.p. injection of $6 \mathrm{mg} / \mathrm{kg}$ body wt. of cisplatin which repeated after 2 weeks for induction of renal failure ${ }^{23} .4$ days later blood samples were collected for creatinine level analysis to estimate the degree of renal deterioration, ${ }^{\mathbf{2 4}-27}$.

\section{Sacrification of the animals in group II was done at $\mathbf{2}$ intervals as follow:-}

Firstly 6 animals were sacrificed after collection of blood samples.

Secondly the remaining 6 animals were sacrificed 1 week later.

Group III: At day zero the animals were received i.p. injection of $6 \mathrm{mg} / \mathrm{kg}$ body wt. of cisplatin once for induction of renal failure, ${ }^{27} .4$ days later blood samples were collected for analysis of creatinine level to estimate the level of renal deterioration ${ }^{24-27}$. Soon after blood analysis, animals of this group were given $5 \mathrm{mg} / \mathrm{kg}$ body wt. $/ \mathrm{day}$ of moringa oleifera extract (by gastric tube) for 2 weeks ${ }^{28}$ (as a possible treatment for acute renal failure). Again blood analysis was done at $14^{\text {th }}$ day of moringa treatment to estimate the efficacy of moringa extract as a prophylaxis.

\section{Sacrification of the animals in group III: was done at 2 intervals as follow:-}

Firstly 6 animals were sacrificed at the end of moringa treatment.

Secondly the remaining 6 animals were sacrificed 1 week later. 
Group IV: At day zero the animals were received i.p. injection of $6 \mathrm{mg} / \mathrm{kg}$ body wt. of cisplatin which repeated after 2 weeks for induction of renal failure, ${ }^{27} .4$ days later blood samples were collected for analysis of creatinine level to estimate the degree of renal deterioration, ${ }^{24-27}$.Soon after blood analysis, animals of this group were given 5 $\mathrm{mg} / \mathrm{kg}$ body wt. /day of moringa oleifera extract (by gastric tube) for 2 weeks (as a possible treatment for renal failure), ${ }^{28}$. Again blood analysis was done to estimate the efficacy of moringa oleifera extract as a treatment.

\section{Sacrification of the animals in group IV was done at 2 intervals as follow:-}

Firstly 6 animals were sacrificed at the end of moringa treatment.

Secondly the remaining 6 animals were sacrificed 1 week later.

\section{Processing of the specimens:-}

The rats were euthanized with over dose halothane and parotid glands were rapidly excised, fixed in $10 \%$ neutral buffered formalin for 24 hours then processed for::

1. Routine histological examination using heamatoxylin and eosin stain, ${ }^{29,30}$.

2. Immunohistochemical staining for caspase 3

Preparation of the extract ${ }^{31}$

\section{Results:-}

\section{Haematoxylin and Eosin Stain Results:-}

Group I: (Control group);-

The control sections of the parotid salivary gland showed the secretory terminal portions (serous acini) which were composed of densely packed pyramidal cells with basophilic cytoplasm. Their nuclei appeared large, spherical and basally situated.Second scarification date was similar to the first one so we just are content with only one.

\section{Group II:-}

At first scarification date:- The parotid sections showed Cracks like vaculations, widening of connective tissue septa, loss of acinar outlines and an obvious hydropic degeneration appeared as multiple vacuoles in /between the acinar cells.

At second sacrifaction date:- The parotid sections showed cracks like vaculations, loss of acinar outlines, an obvious hydropic degeneration appeared as multiple vacuoles in between the acin ai with wide spaces between the lobules.

\section{Group III:-}

At first scarification date:- On the examination of this group, the parotid gland sections showed densely packed serous acini, nuclei have symmetrical shape and size, disappearance of the wide connective tissue septa in between lobules and the outlines of acini appeared polyhedral in shape.

At second sacrifaction date:- The histological sections showed densely packed rounded acini, Regular basally located nuclei with symmetrical shape and size restoring its normal pattern.

\section{Group IV:-}

At first scarification date:- On the examination of this group, the histological sections showed wide interlobular and intralobular spaces separating the acini, the acini have irregular shapes and sizes and inter calated duct with degenerated epithelial lining.

At second sacrifaction date:- The parotid gland sections showed densely packed serous acini with connective tissue septa in between lobules, the outlines of acini have different shapes and the acini showed regular basally located nuclei restoring its normal pattern. 


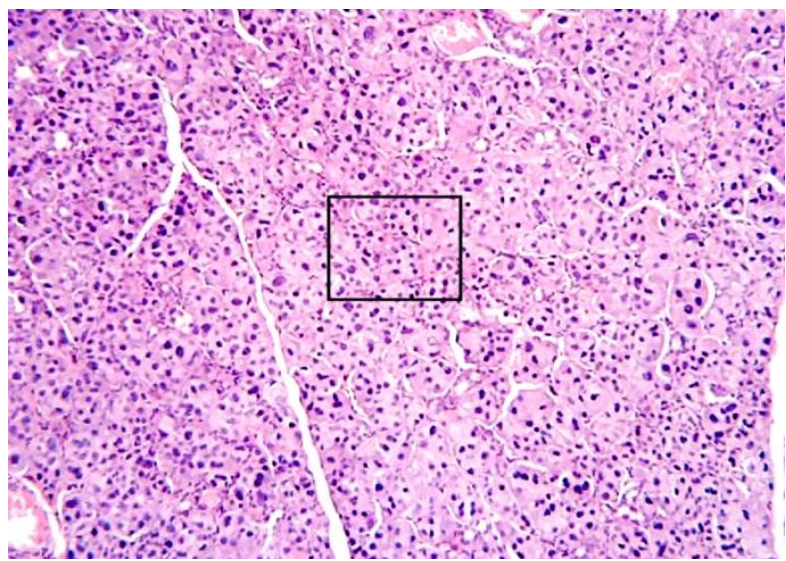

Figure 1

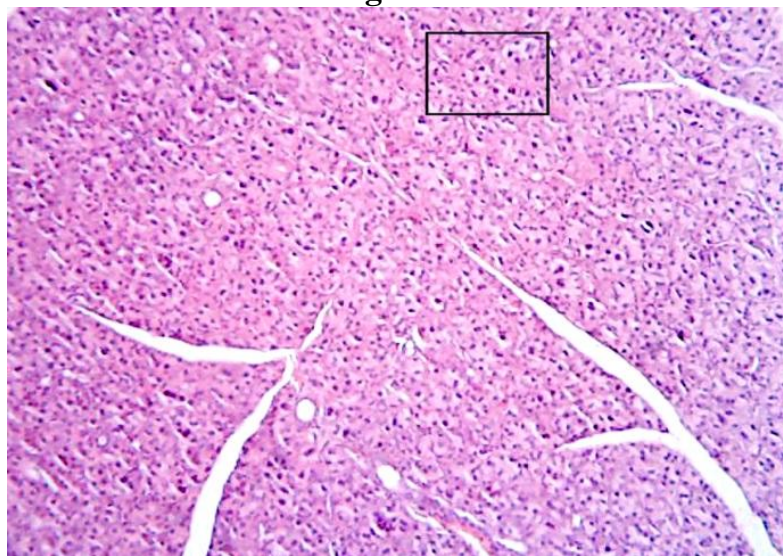

Figure 3

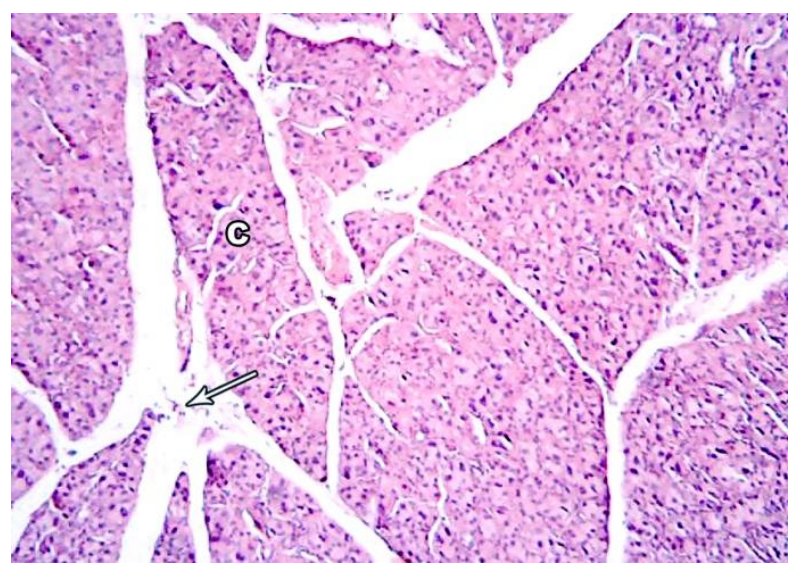

Figure 2

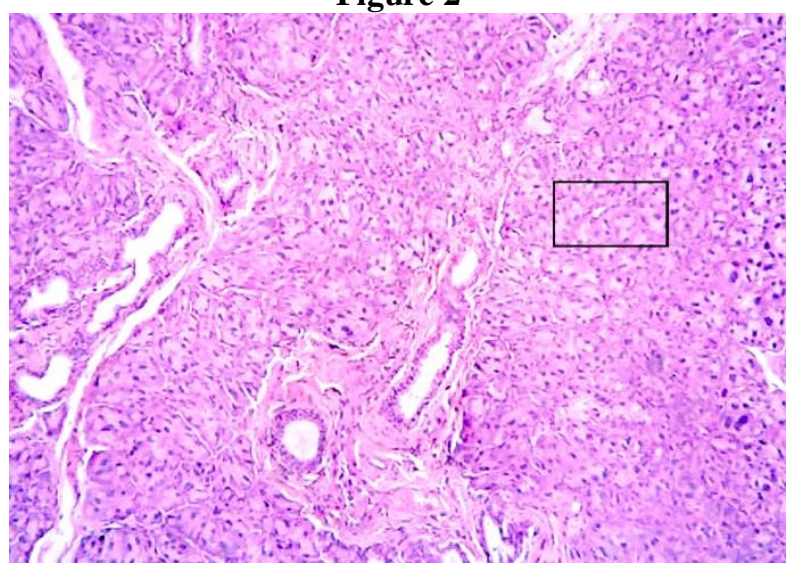

Figure 4

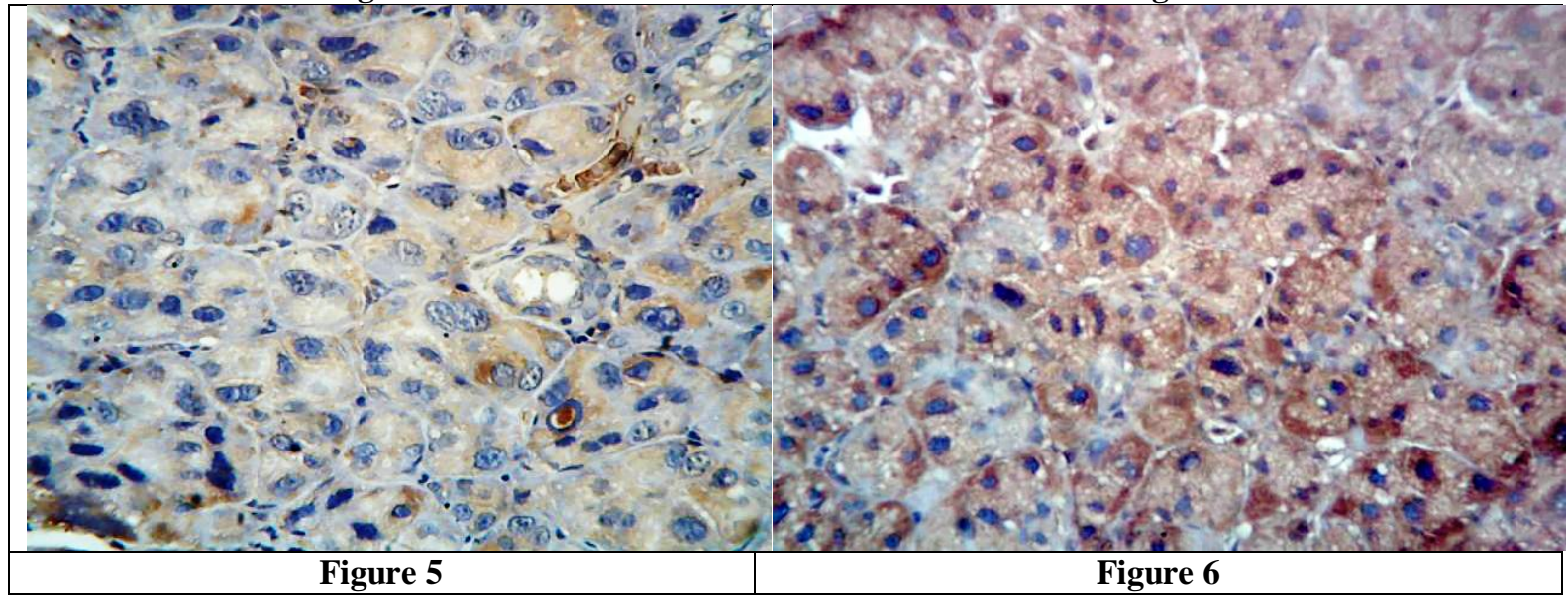




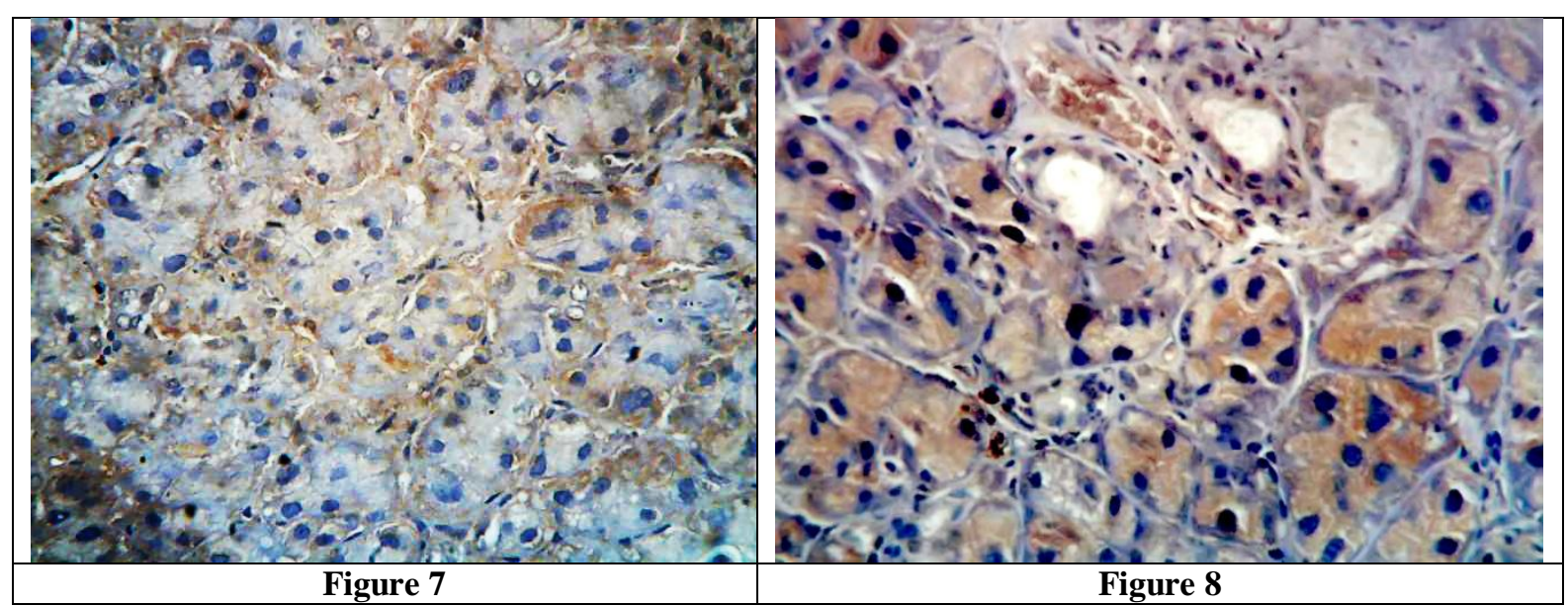

Fig (1):Photomicrograph of parotid gland section group Ishowing densely packed acinar cells with large basally located nuclei (SA) (H\&E stain, x100).Fig (2):Photomicrograph of parotid gland section group II at second scarification date showing cracks (C) and widening of connective tissue septa $(\rightarrow)$ (H\&E stain, x100).Fig (3):Photomicrograph of parotid gland section group III at second scarification date showing round serous acini with regular basally located nuclei with symmetrical shape and size.Fig (4): Photomicrograph of parotid gland section group IV at second scarification date showing round serous acini with regular basally located nucleirestoring its normal pattern. Fig (5): photomicrograph of the control group showing mild reaction of caspase 3, the reaction could be seen hardly in the cytoplasm of some nuclei (Immunoperoxidase staining with anti-caspase 3 antibody, DAB chromagen X400).Fig (6): photomicrograph of the group II at second sac. date showing more intense reaction of caspase 3 in the cytoplasm of acinar cells.Fig (7): photomicrograph of the group III at second sac. date showing moderate reaction of caspase 3 in the peripheral cytoplasm of the acinar cells. Fig (8): photomicrograph of the group IV at second sac. date showing moderate reaction of caspase 3 in the cytoplasm of the acinar cells.

\section{Discussion:-}

The protective action of flavonoids against oxidative stress induced cellular damage has been proved bymany previous studies. The potent antioxidant activity of flavonoids may be their most important function. Flavonoids can exert their antioxidant activity by various mechanisms, e.g., by scavenging or quenching free radicals, by chelating metal ions, or by inhibiting enzymatic systems responsible for free radical generation, ${ }^{\mathbf{3 2}}$. The antioxidant property also can be due to the presence of carotenoids, alkaloids, and proanthocyanidins in this plant, ${ }^{33}$.

As it was proved that the antioxidant effect and renal protectant activity of Moringa leaves, ${ }^{34}$ this study was conducted to evaluate the effect of Moringa Oleifera extract on parotid gland of cisplatin- induced renal failure in albino rats. In the present study moringa was administered orally via a gastric tube in a dosage of $5 \mathrm{mg} / \mathrm{kg}$ body wt. /day for two weeks in group III after single dose of cisplatin and in group IV after double dose of cisplatin.

The control group of the parotid gland sections stained with H \& E showed the normal histology of the serous acini, while in group II after $1^{\text {st }}$ and $2^{\text {nd }}$ scarification dates there were widening of connective tissue septa, loss of acinar outlines and an obvious hydropic degeneration and these results were also reported by (Rabab Mubarak and Zoba H. Ali, 2012) who proved the protective effects of L-Carnitine on cisplatin induced toxicity in rat parotid salivary glands and observed that cisplatin produce enlarged, ill-defined outline of the parotid acini with numerous intracellular vacuoles, ${ }^{35}$.

(Kitashima S., 2005) attribute the numerous intra cytoplasmic vacuoles either to intra cytoplasmic degenerative changes within the acinar cells or due to fusion of the secretory granules, aggregation of the secretory granules within the secretory cells was thought to be due to enhanced salivation in order to eliminate cisplatin shortly after infusion, ${ }^{36}$.

The exact mechanism of cisplatin - induced nephrotoxicity is not completely understood. However, oxidative stress and production of reactive oxygen species (ROS) has been found to be involved in the pathogenesis of cisplatin induced renal damage, ${ }^{37,38}$. Mansour et al., showed that significant decline in antioxidant enzymes activities and increase in free radicals has been observed both experimentally and clinically during cisplatin treatment, ${ }^{39}$.Cisplatin 
can induce renal proximal tubule cellular (RPTC) damage which develop after one dose and may result in either acute renal failure and/or renal electrolyte wasting, ${ }^{\mathbf{4 0}, \mathbf{4 1}}$.

In $\mathrm{H} \& \mathrm{E}$ stain results of group III that treated with moringa after single dose of cisplatin, the $1^{\text {st }}$ and $2^{\text {nd }}$ scarification dates showed densely packed serous acini, nuclei have symmetrical shape and size, disappearance of the wide connective tissue septa in between lobules and the outlines of acini appeared polyhedral in shape, these findings comes in accordance with (Visavadiya, NP and Narasimhacharya, AV R.L., 2005) who proved the antioxidant activity of moringaoleifera extract through its antioxidant enzymes, mainly superoxide dismutase and catalase are first line defensive enzymes against free radicals. In their study they were observed that the Moringa olifera extract significantly increases antioxidant parameters in acetic acid induced colitis in albino rats, ${ }^{\mathbf{4 2}}$.

As for immunohistochemical results, the anti- caspase 3 showed mild reaction in the cytoplasm of some acini and this reaction may be due to the fact that apoptosis enables the body to kill and remove the unwanted cells during animal development, normal homeostasis and disease. In group II at $1^{\text {st }}$ scarification date the reaction was intense and in the $2^{\text {nd }}$ scarification date it was more intense in the acinar cells indicating severe degree of apoptosis, these findings come in accordance with (Kang, et al., 2009), who investigate the effect of Sildenafil on renal injury in an experimental model of rat cisplatin-induced nephrotoxicity, they were noticed that the expression of active caspase-3 was increased significantly in the kidneys of rats treated with cisplatin compared with the expression in the kidneys from control and Sildenafil groups, ${ }^{43}$.

In an expected results for group III at $1^{\text {st }}$ scarification date showed mild reaction of anti- caspase 3 surrounding the nuclei of the acinar cells in comparison to group II indicating reduction in the amount of apoptosis induced by cisplatin which may be interpreted by the protective action of moringa extract, while at $2^{\text {nd }}$ scarification date there was moderate reaction of caspase 3 in the peripheral cytoplasm of the acinar cells, these findings was in agreement with (Afzal, et al., 2014), who investigate the effect of moringa leaves on arsenic-induced toxicity in mice, when they reported that moringa leaf is a safe natural antioxidant containing vegetable and is found as a potential source of four natural antioxidants such as total phenolics antioxidant, vitamin A,C, and E. So ingredients of the moringa leaves inhibited arsenic-induced reactive oxygen species production which ultimately abrogated the signaling pathways associated with toxicity of arsenic, ${ }^{44-46}$.

Moreover, group IV at $1^{\text {st }}$ scarification date showed intense reaction of anti- caspase 3 in the cytoplasm of serous acini, while at $2^{\text {nd }}$ scarification date there was moderate reaction of caspase 3 in the cytoplasm of acinar cells in comparison to group II indicating decrease in the degree of apoptosis and ensuring the anti-oxidant action of moringa oleifera.

(Subhadeep et al., 2014), investigate the apoptotic activity of ethanolic extract of moringa oleifera root bark on human myeloid leukemia cells via activation of caspase cascade and find that moringa preferentially kills leukemic cells (particularly those of histiocytic lymphoma and erythroblastic cells) by triggering programmed cell death. Moringa oleifera induced cytotoxicity leading to altered DNA fragmentation and enhanced caspase activation, ${ }^{47}$.

One way-ANOVA statistical test for serum creatinine after the $1^{\text {st }}$ and $2^{\text {nd }}$ blood analysis revealed significant increase in group II followed by group IV and the lowest one was for group I followed by group III, suggesting the improvement in group III results at $1^{\text {st }}$ and $2^{\text {nd }}$ scarification dates in comparison to group II and IV. These findings proved the anti-oxidant protective effect of moringa against cisplatin induced renal failure especially in acute cases represented by group III and these results were supported by (Mona S. Halaby et al., 2013)who proved that moringa oleifera at high concentration improved the nutritional value and realized the best effect on serum lipids and kidney functions in hyper-lipidemic rats, as in her studies there were significant reduction in creatinine level than that of the positive control group, ${ }^{48}$.

From the previous results we can conclude that moringa was found to be an effective herbal medicine in the animal models of renal failure. From our study we demonstrated the renal protectant activity of moringa, its toxic effects and undesired properties are none or minimal. 


\section{Conclusion:-}

Based on the pervious results we conclude that:

$>$ Renal failure produce cracks, vaculations, hydropic degeneration and widening of connective tissue septa in the parotid gland.

> Moringaoleifera extract can ameliorate the nephrotoxic effect on the parotid gland in cases of acute renal failure better than cases of chronic renal failure.

\section{References:-}

1. Kersten L, Br"aunlich H, Keppler BK, Gliesing C, Wendelin M and Westphal J. Comparative nephrotoxicity of some antitumor-active platinum and ruthenium complexes in rats. J ApplToxicol1998; 18:93-101.

2. Arjumand, W., Seth, A. and Sultana, S.Rutin attenuates cisplatin induced renal inflammation and apoptosis by reducing NFjB, TNF- and caspase-3 expression in Wistar rats. Food Chem. Toxicol. 2011; 49, 2013-2021.

3. Masuda, H., Tanaka, T. and Takahama, U. Cisplatin generates superoxide anion by interaction with DNA in a cellfree system. Biochem. Biophys. Res. Commun. 1994; 203, 1175-1180.

4. McKeage MJ. Comparative adverse effect profiles of platinum drugs. Drug Saf.1995; 13: 228-244.

5. Devarajan P, Savoca M, Castaneda M, Park M, Esteban-Cruciani $\mathbf{N}$ andKalinec $\mathbf{G}$ et al. Cisplatin induced apoptosis in auditory cells: role of death receptor and mitochondrial pathways. Hear Res., 2002; 174: 45-54.

6. Cardinaal R, De Groot J, Huizing E, SmoorenburgG and VeldmanJ. Ultra structural changes in the albino guinea pig cochlea at different survival times following cessation of 8-day cisplatin administration. Acta Otolaryngol.2004; 124: $144-154$.

7. Rybak L, Husain K, Whitworth C and Somani SM. Dose dependent protection by lipoic acid against cisplatininduced ototoxicity in rats: antioxidant defense system. Toxicol Sciences, 1999; 47: 195- 202.

8. Fahey, J., Kostova D., Talalay P. The "Prochaska" micro titer plate bioassay for inducers of NQO1. Chapter 14 in Methods in Enzymology, 2004; 382: 243-258.

9. Farooq, F., RaiM.,Tiwari A., KhanA. And Farooq S. Medicinal properties of Moringaoleifera: An overview of promising healer. J. of Medicinal Plants Research, 2012; 6(27): 4368-4374.

10. Moringaolifera, Pharmainfo.net, available in: http://www. Pharmainfo.net/reviews/moringa-oleifera-lam-miracletree (accessed on 20/02/2012).

11. FuglieLJ.New Uses of Moringa Studied in Nicaragua. ECHO Development Notes \#68, June, 2000.

12. Juri Bora Borgohain \& Lakhinandan Borgohain. Moringa oleifera. Bonsaak Aru Iyar Byobohar.1st ed. Dibrugarh: Banalata Publisher India; 2010. P-26-27.

13. Siddhuraju P and Becker K. Antioxidant properties of various solvent extracts of total phenolic constituents from three different agro climatic origins of drumstick tree (Moringaoleifera Lam.) leaves. J Agric Food Chem 2003; 51: 2144-55.

14. Bimala Patawari. Moringa_oleifera. A glossary of medicinal plants of Assam \& Meghalaya. Guwahati. N. Printers; 1992 , p.87.

15. Khatun S, Absar N and Ashraduzzaman M. Changes in physic chemical compositions and activities of some hydrolytic and oxidative enzymes in the two types of sajna (Moringa oleiferaLam.) leaves at different maturity levels. Indian J Plant Physiol2003; 8(1): 6-11.

16. Yang $\mathbf{C}$ and Frenkel K. Arsenic-mediated cellular signal transduction, transcription factor activation, and aberrant gene expression: implications in carcinogenesis. J Environ PatholToxicolOncol2002; 21: 331-342.

17. Makkar HP and Becker K. Nutrients and anti-quality factors indifferent morphological parts of the Moringa oleifera tree. J Agric Sci Cambridge 1997; 128: 311-322.

18. Ghasi S, Nwobodo E and Offili JO. Hypo-cholestrolemic effects of crude extracts of leaf of Moringa oleifera Lam. in high fat diet fed Wister rats. J Ethanopharmacol2000; 69: 21-25.

19. Tahiliani $\mathbf{P}$ andKar A. Role of Moringa oleifera leaf extract in the regulation of thyroid hormone status in adult male and female rats. Pharmacol Res 2000; 41: 319-23.

20. Makonnen E, Hunde A andDamecha G. Hypoglycemic effect of Moringa steno petala aqueous extract in rabbits. Phytother Res 1997; 11: 147-148.

21. Murakami A, Kitazono Y, Jiwajinda S, Koshimizu $\mathbf{K}$ andOhigashi H. Niaziminin, a thiocarbamate from the leaves of Moringa oleifera, holds a strict structural requirement for inhibition of tumor promoter-induced Epstein-Barr virus activation. Planta Med1998; 64(4): 319-323.

22. Faizi S, Siddiqui BS, Saleem R, Siddiqui S, Aftab K andGilani AH. Fully acetylated carbamate and hypotensive thiocarbamate glycosides from Moringa oleifera. Phytochemistry1995; 38(4): 957-963.

23. Nishihara K, Masuda S, Nakagawa S, Yonezawa A, Ichimura T and Bonventre J.V. , etal., Impact of cyclin B2 and cell division cycle 2 on tubular hyperplasia in progressive chronic renal failure rats. Am J physiol Renal physiol, 2010; 298, pp. F923-F934. 
24. Sueshi K, Mishima K, Makino K, Itoh Y, Tsuruya K, Hirakata H and Oishi R. Protection by a radical scavenger edaravone against cisplatin-induced nephrotoxicity in rat. Eur J Pharmacol, 2002; 451: 203-208.

25. Mora LO, Antunes LM, Francescato HD and Bianchi ML. The effects of oral glutamine on cisplatin-induced nephrotoxicity in rats. Pharmacol Res, 2003; 47: 517-522.

26. Ichimura T, Hung CC, Yang SA, Stevens JL and Bonventre JV. Kidney injury molecule-1: a tissue and urinary biomarker for nephron toxicant-induced renal injury. Am J Physiol Renal Physiol, 2004; 286 : F552-F563.

27. Lee DW, Kwak IS, Lee SB, Song SH, Seong EY, Yang BY, Lee MY and Sol MY. Post-treatment effects of erythropoietin and nor di hydro guaiaretic acid on recovery from cisplatin-induced acute renal failure in the rat. $\mathbf{J}$ Korean Med Sci, 2009, 24, 170-175.

28. Sinha M, Das DK, Bhattacharjee S, Majumdar S and Dey S. Leaf extract of Moringa oleifera prevents ionizing radiation-induced oxidative stress in mice. J Med Food. 2011; 14 (10):1167-1172.

29. Glauert AM. Fixation, dehydration and embedding of biological specimens. Amsterdam; Elsevier North Holland, 1987, P: 5-110.

30. Baker and Silverton's. Introduction to medical laboratory technology, 1998, 7th ed., chap.12, P: 182-193.

31. Clark WE. Extracta Liquida Pharmaceutical Formulations. In: Le G, editor. The Chemist and Druggist Book. London: Essex Street Strand; 1950.p.183.

32. Lukacinova A, Mojzis J, Benacka R, Keller J, Maguth T and Kurila P. Preventive Effects of Flavonoids on Alloxan-Induced Diabetes Mellitus in Rats. Acta Vet 2008; 77:175-182.

33. Jyotsna Mishra, Srivastava R.K., Shukla S.V. and Raghav C.S. Antioxidants in aromatic \& medicinal plants. Science Tech entrepreneur July 2007.

34. Glauert AM. Fixation, dehydration and embedding of biological specimens. Amsterdam; Elsevier North Holland, 1987, P: 5-110.

35. Rabab Mubarak and Zoba H. Ali. Protective Effects of L-Carnitine on Cisplatin Induced Toxicity In rat Parotid Salivary Glands Journal of American Science 2012; 8(2).

36. Kitashima S. Morphological alterations of submandibular glands caused by cisplatin in the rat. Krume Medical Journal, 2005; 52: 29-38.

37. Davis, C.A., Nick, H.S., Agarwal, A. Manganese superoxide dismutase attenuates Cisplatin-induced renal injury: importance of superoxide. J. Am. Soc. Nephrol.2001; 12: 2683-2690.

38. Luo, J., Tsuji, T., Yasuda, H., Sun, Y., Fujigaki, Y., Hishida, A. The molecular mechanisms of the attenuation of cisplatin-induced acute renal failure by N-acetyl cysteine in rats. Nephrol Dial Transplant.2008; 23:198-205.

39. Mansour, H.H., Hafez, H.F., Fahmy, N.M. Silymarin modulates cisplatin-induced oxidative stress and hepatotoxicity in rats. J Biochem Mol Biol. 2006; 39:656-61.

40. Safirstein R, Miller P, and Gutten plan JB. Uptake and metabolism of cisplatin by rat kidney. Kidney Int; 1984, 25:753-758.

41. Lau AH. Apoptosis induced by cisplatin nephrotoxic injury. Kidney Int; 1999, 56:1295-1298.

42. Visavadiya, NP and Narasimhacharya, AV R.L. Hypolipidemic and antioxidant activities of Asparagus racemosus in hyper cholesteremic rats. Indian J Pharmacol 2005; 37(6):376-80.

43. KangWookLeea, Jin Young Jeonga, Beom Jin Limb, Yoon-Kyung Changc, Sang-JuLeec, Ki-RyangNaa, Young-Tai Shina and DaeEunChoia. Sildenafil attenuates renal injury in an experimental model of rat cisplatininduced nephrotoxicity, Toxicology 257, 2009; 137-143.

44. Afzal Sheikh, FouziaYeasmin, SmitaAgarwal, MashiurRahman, Khairul Islam, EkhtearHossain, ShakhawoatHossain, MdRezaulKarim, FarjanaNikkon, ZahangirAlam Saud and KhaledHossain. Protective effects of Moringa oleifera Lam. leaves against arsenic-induced toxicity in mice. Asian Pac J Trop Biomed 2014; 4(Suppl 1): S353-S358.

45. Perumal S and Klaus B. Antioxidant properties of various solvent extracts of total phenolic constituents from three different agro climatic origins of drumstick tree (Moringa oleifera Lam.) leaves. J Agric Food Chem 2003; 51(8): 2144-2155.

46. Yang R, Chang L, Hsu J, Weng BB, Palada MC and Chadha ML, et al. Nutritional and functional properties of moringa leaves - from germplasm, to plant, to food, to health. Washington D.C.: American Chemical Society; 2006, p. $1-17$.

47. Subhadeep Roy, Nilanjana Deb, SantanuBasu and Shila Elizabeth Besra. Apoptotic activity of ethanolic extract of moringa oleifera root bark on human myeloid leukemia cells via activation of caspase cascade. 2014, Vol 3, Issue 10.

48. Mona S. Halaby, Eman M. Elmetwaly and Aya A.A. Omar. Effect of MoringaOleifera on serum lipids and kidney function of hyper-lipidemic rats. Journal of Applied Sciences Research; 2013, 9(8): 5189-5198. 